\section{Factors Influencing Home Lawn Fertilizer Choice in the United States}

\author{
Julie Campbell ${ }^{1}$, Alicia Rihnn ${ }^{2}$, and Hayk Khachatryan ${ }^{3}$
}

ADDITIONAL INDEX WORDS. consumer preferences, marketing, organic, purchase behaviors, sustainable

SUMMARY. Home lawn fertilizer use throughout the United States is coming under increased scrutiny due to potential negative environmental impacts. A better understanding of how consumer perceptions and socio-demographics impact their choices of types of lawn fertilizers can aid industry stakeholders when marketing products. This research uses a nationwide survey to evaluate factors that impact respondents' choice of lawn fertilizer brands. Respondents with home lawns selected the lawn fertilizer brands they purchased the most frequently and rated the importance of various fertilizer attributes (e.g., nitrogen-phosphorus-potassium ratio, brand, price, etc.) when selecting lawn fertilizers. Given many lawn fertilizer brands share commonalities, respondents' answers were grouped into five categories: most popular brand, primarily turf brands, sustainable/organic brands, other brands, and "I don't remember the brand." The most popular brand of fertilizer was chosen by $69 \%$ of respondents, with the primarily turf brands and other fertilizers being chosen by $25 \%$ and $23 \%$ of respondents, respectively. This study finds that brand selection is impacted by important fertilizer features, frequented retail outlets, geographical region of residence, and demographic variables. For example, brand importance and purchasing from mass merchandisers or wholesale clubs increased respondents' selection likelihood of the most popular brand by $6.9 \%$ and $20.5 \%$ points, respectively. Marketing implications are discussed.

I $\mathrm{n}$ the United States, managed turfgrass encompasses almost $2 \%$ of the total land area, and $25 \%$ of urban landscapes are devoted to lawns (Milesi et al., 2005). Even though only a portion of these lawn areas are fertilized (Wheeler et al., 2017), and the intensity of fertilization can vary significantly (Larson et al., 2016; Polsky et al., 2014), home lawn fertilization has been the subject of considerable research pertaining to water quality and other environmental factors (Carey et al., 2012; Groffman et al., 2016). Given this importance, understanding

Received for publication 11 July 2019. Accepted for publication 22 Nov. 2019.

Published online 14 April 2020.

${ }^{1}$ Department of Horticulture, University of Georgia, 325 Hoke Smith Building, Athens, GA 30602

${ }^{2}$ Mid-Florida Research and Education Center, University of Florida, 2725 S. Binion Road, Apopka, FL 32703

${ }^{3}$ Food and Resource Economics Department and Mid-Florida Research and Education Center, University of Florida, 2725 S. Binion Road, Apopka, FL 32703

This research was supported by the Center for Landscape Conservation and Ecology at the University of Florida.

H.K. is the corresponding author. E-mail: hayk@ufl. edu.

This is an open access article distributed under the CC BY-NC-ND license (https://creativecommons.org/ licenses/by-nc-nd/4.0/).

https://doi.org/10.21273/HORTTECH04454-19 the factors that influence residential fertilizer purchasing decisions could lead to greater mindfulness in mitigating some of the environmental issues associated with home lawn fertilization.

Depending on the intensity and quality of the turfgrass management practices, lawns can provide many environmental and social benefits. Turfgrass has been shown to sequester carbon (Bandaranayake et al., 2003; Milesi et al., 2005; Qian and Follett, 2002), which potentially slows climate change (Lal, 2004). Turfgrass also reduces surface and ambient air temperatures, enhances the capture of water runoff, reduces soil erosion, improves soil health, decreases pests and pollens, lowers fire hazards, improves security (via increased visibility), improves human health, and increases recreational opportunities while providing aesthetic benefits (Beard, 1999; Beard and Green, 1994; World Health Organization, 2016). Proper fertilization is essential in establishing and maintaining healthy turfgrass lawns (Hochmuth et al., 2012). However, residential fertilizer use throughout the United States is beginning to be scrutinized due to potential environmental impacts from excessive use of micro- and macronutrients. For example, improper fertilization practices have been connected to nonpoint source water pollution, which can lead to algal blooms and depleted oxygen levels in waterways (Carrico et al., 2013; Cook et al., 2012; Martini et al., 2015; Reid et al., 2010; Robbins and Birkenholtz, 2003; Robbins and Sharp, 2003). This has led to increased scrutiny from state and local regulators who have implemented restrictions and fertilizer bans to reduce potential pollution issues (Miller, 2012; Wallace et al., 2016).

Many states have begun to regulate the use of chemicals and fertilizers. For instance, Connecticut and New York have banned the use of pesticides on kindergarten through eighth-grade turfgrass areas at schools (Wallace et al., 2016). Furthermore, Florida, Illinois, Maine, Maryland, Michigan, Minnesota, New Jersey, New York, Vermont, Virginia, Washington, and Wisconsin have regulations that control fertilizer use on residential turfgrass (Miller, 2012). Though these regulations have good intentions, they create issues for homeowners and managers of turfgrass fields when trying to effectively manage their turfgrass. One issue is lower turfgrass quality if nutrients are not available and fertilizers cannot be applied when the plants need them, such as during the primary growing season (Hochmuth et al., 2012). This can result in weaker plants that are more susceptible to disease, pests, damage, and erosion. Conversely, an overabundance of nutrients can result in water pollution. This can occur when nutrients leach through or runoff the soil and enter water bodies, which can contribute to eutrophication and algae blooms (Hochmuth et al., 2012).

Beyond environmental concerns, there is also intense competition within the home lawn fertilizer industry as firms look to expand their market share and increase sales. One means of firms gaining a competitive advantage is to align their fertilizer traits with receptive market segments (i.e., target marketing). With respect to the current market, Dahlin et al. (2016) found five fertilizer buyer segments in Germany (price sensitive buyer, universal product buyer, price sensitive green buyer, multi-criteria buyer, and premium product buyer). Of interest, the fertilizer brand name ranged between $7 \%$ and $9 \%$ of the buying decision for four of the 
segments but was $46 \%$ of the buying decision for the premium product buyer segment. Furthermore, organic fertilizers were preferred by three of the segments. This aligns with Khachatryan et al. (2016), who found that eco-friendly fertilizer attributes positively influence homeowners' preferences and willingness to pay for fertilizers. Consequently, many factors impact homeowners' fertilizer preferences and ultimately selection, which in turn can impact turfgrass and environmental health.

As lawn fertilizer brands look to maintain and grow sales in the United States, fertilizer producers and retailers need to understand how consumer demographics and fertilizer attributes impact homeowners' purchasing decisions. Previously, Suh et al. (2016) demonstrated that educational campaigns could increase purchasing frequency of organic/natural fertilizers, meaning there is potential to use consumer preference information to more effectively target specific groups of consumers. However, little research has examined the role of demographics and fertilizer attributes on fertilizer brand selection. This article looks to fill this gap by assessing which fertilizer brand categories (i.e., most popular, sustainable/organic brands, etc.) are selected by homeowners as well as understanding how varying demographics, important attributes, and frequented retail outlets impact brand purchasing behavior. Further, the home lawn fertilizer industry can use the results to better understand how consumer groups vary among preferred fertilizer brand categories. Perhaps just as important, this study examines the "I don't remember the brand" group of consumers who may not be brand loyal but are important for firms wanting to increase their market share and sales.

The importance of assessing consumer purchasing behavior toward various fertilizers is 2 -fold. First, there is a growing trend to brand products as "environmentally friendly" or "green" to appeal to consumers who are more environmentally conscious. This is driven by several factors; notably, there has been increased scrutiny of turfgrass management due to incorrect or misunderstood maintenance practices and their potential negative effects on the environment and human health. Many home lawns and athletic fields are managed using inputs such as fertilizers, pesticides, and irrigation to optimize growth and control potentially devastating pests (King et al., 2007). Routine use of these inputs has led to the perception that turfgrass is a major nonpoint source water pollution contributor (Beverly et al., 1997). In fact, maintaining turfgrass to fulfill today's aesthetic norms often requires intensive irrigation, mowing, and the application of chemicals, which can result in a multitude of environmental impacts (Kjelgren et al., 2000; Priest et al., 2000; Reid et al., 2010). Notably, use of fertilizer on home lawns by do-ityourself (DIY) homeowners has led to environmental problems such as algal blooms and depleted oxygen levels in local waterways from excessive use of micro- and macronutrients (Carrico et al., 2013; Cook et al., 2012; Martini et al., 2015; Robbins and Birkenholtz, 2003; Robbins and Sharp, 2003).

Second, there is growing consumer sentiment toward more eco- or environmentally friendly alternatives as being socially acceptable. Thus, some firms are beginning to position themselves as eco-friendly alternatives to conventional fertilizer options. Eco-friendly fertilizers potentially offer the benefits of containing less environmentally damaging ingredients than traditional fertilizers (Berndt et al., 1990; Cheng et al., 2008; Duble, 1996; Liu et al., 1995; McCoy, 1998). Notably, eco-friendly alternatives may contain natural and/or organic ingredients, be phosphorousfree, have controlled-nutrient release rates, and aid with integrated pest management strategies to improve turfgrass health (Bruneau et al., 2008; Morris and Bagby, 2008). Similar value-added attributes may or may not be offered in other fertilizer options.

As firms position themselves in the marketplace, there is constant competition to maintain brand recognition while meeting changing consumer needs. Firms and policymakers looking to drive increased use of eco-friendly alternatives need to focus on educational efforts to increase use by DIY homeowners (Carey et al., 2012; Easton and Petrovic, 2004). The effectiveness of educational efforts can be enhanced through a better understanding of current DIY homeowners' preferences, perceptions, and behaviors related to home lawn fertilizer brands. Unique contributions of this study are the elucidation of factors that influence lawn fertilizer brand category choice. Specifically, contributions include the use of real lawn fertilizer brand options to assess brand choice, an in-depth analysis of the relationship between important value-added attributes and brand choice, and an assessment of the relationship between retail outlet and brand choice. To date, other studies have primarily focused on value-added attributes and consumer perceptions of fertilizers rather than the fertilizer brand selection (Carrico et al., 2013; Dahlin et al., 2016; Khachatryan et al., 2016; Martini et al., 2015; Suh et al., 2016). Overall, our article aids in quantifying homeowners' lawn fertilizer brand choices and the factors that influence those preferences.

\section{Materials and methods}

Data were collected using an online survey in Dec. 2013 to measure U.S. homeowners' fertilizer usage and brand preferences. Survey software (Qualtrics, Provo, UT) was used as the platform to develop and distribute the survey. Survey respondents were selected from Qualtrics' online panelist database. The advantages of an online sample include faster, less expensive, more accurate information with less human error, but a major disadvantage is sampling bias. Sampling bias occurs if some homeowners are not represented in the sample or if the sample consists of "professional survey takers" (Campbell et al., 2016; Cobanoglu et al., 2001; Dillman et al., 2009; McCullough, 1998). In this study, validation questions were used to prevent sample bias from professional survey takers. An example of one of the validation questions is "To ensure that you are reading the statements, please choose 'slightly disagree' as your answer to this statement." If the respondent answered the validation questions incorrectly, she or he was removed from the sample. Because the Qualtrics' panel is very large, sampling bias is likely limited, and the likelihood of the sample accurately representing U.S. homeowners is increased. 
Screening questions were used to filter out irrelevant respondents. To qualify for the study, respondents were asked a set of three screening questions. Screening questions and answer options included the following: 1) Does your home have a lawn? (yes/no); 2 ) How do you usually fertilize your lawn? (purchase/apply fertilizer yourself, pay a professional lawn care company, pay someone other than a lawn care company, your lawn is not being fertilized); and 3 ) Have you purchased lawn fertilizers in the past 12 months? (yes/no). Only homeowners who had a lawn, had applied fertilizer to their lawn themselves (DIY homeowners), and had purchased lawn fertilizer in the past 12 months qualified. These individuals were of interest because lawn fertilizers are only relevant for people who have lawns, and the homeowners' awareness of the brand of fertilizer is likely heightened for those who fertilize their own lawns. If someone hires a firm to care for his/her lawn, the homeowner likely does not know the type or brand of fertilizer used. Therefore, the screening questions serve to eliminate irrelevant responses and capture existing lawn fertilizer market perceptions.

The dataset used in this manuscript was from a larger survey addressing U.S. homeowners' preferences for residential lawn fertilizers. Specific to this article, several lawn fertilizer-related questions were included in the survey that pertained to brand, important attributes, purchase location, and sociodemographics. Respondents were asked to indicate which lawn fertilizer brands they purchased most frequently. They could select more than one brand. Answer options were based on online and in-person evaluations of available products at the time of the study. The fertilizer list consisted of 11 major lawn care category name brands within the traditional and ecofriendly realm, an "other" option, and an "I don't remember the brand" option. (Brand names are not provided here to avoid potential trademark issues. The specific brand names used in this study are available on request from the corresponding author.) The fertilizer brand list was randomized to reduce any potential order effect. Given that many brands share commonalities, for analysis, the brands were sorted into five categories depending upon consumer-stated recognition and how the brands were marketed/labeled on their company websites. Categories included the most popular brand, primarily turf brands, sustainable/organic brands, other brands, and "I don't remember the brand." Consumer-stated recognition was used to develop the most popular brand category, which consisted of a single brand that was selected by a large portion (69\%) of the sample. The fertilizers' marketing or labeling was used to create three other categories (i.e., primarily turf brands, sustainable/organic brands, and other brands), where the brands were divided into categories based on an analysis of the packaging and online promotional elements. By this we mean that if the brand's packaging or website emphasized certain traits (e.g., turf, organic, etc.), that brand was assigned to the corresponding broader brand category. Three brands were included in the "turf" category because they were primarily marketed as turf fertilizer brands. Three different brands were included in the sustainable/organic fertilizers category, which emphasized environmentally friendly, natural, or organic components. The other fertilizers category consisted of four fertilizer brands and the "other" answer option. These fertilizers were not clearly marketed as turf or environmentally friendly and likely included regionally popular fertilizer options. Lastly, the "I don't remember the brand" category was assigned to respondents that selected that option.

Respondents were asked about the importance of different fertilizer attributes (where one equaled very unimportant, three equaled neutral, and five equaled very important). The list of fertilizer attributes was based on product labeling requirements [e.g., nitrogen-phosphorus-potassium $(\mathrm{N}-\mathrm{P}-\mathrm{K})$ ratio, size, etc.] and value-added attributes (e.g., water smart technology, insecticide included, etc.). Fertilizer attributes included N-P-K ratio, brand, bag size, price, organic, controlled-release $\mathrm{N}$, insecticide included, herbicide included, pet- and kid-friendly, fertilizer effect longevity, quick acting, and water smart. The fertilizer attributes were presented in a random order to reduce any order effects.
Respondents indicated the retail outlet where they usually purchase lawn fertilizers. Answer options included independent garden centers, supermarket or grocery stores, home improvement or hardware stores, mass merchandiser or wholesale club, Internet, and other ("please list"). For analysis, the location of fertilizer purchases was coded in binary, where one indicates selection and zero otherwise. For instance, if the respondent indicated that $\mathrm{s} /$ he purchase the fertilizer from an independent garden center, the independent garden center variable would equal one. Conversely, if another respondent did not select independent garden center, that variable would equal zero.

Lastly, the sociodemographic questions included age, gender, education level, number of adults per household, number of children $(<18$ years) per household, if there were pets that played in the lawn, income, and state of residence. The states of residence responses were divided into four U.S. regions: western, midwestern, southern, and northeastern (U.S. Census Bureau, 2019a). States in the western region included Arizona, California, Colorado, Idaho, Montana, New Mexico, Nevada, Oregon, Utah, Washington, Wyoming, Alaska, and Hawaii. Midwestern states included Indiana, Iowa, Illinois, Kansas, Minnesota, Michigan, Missouri, Nebraska, North Dakota, Ohio, South Dakota, and Wisconsin. Southern states included Alabama, Arkansas, Florida, Georgia, Kentucky, Louisiana, Maryland, Mississippi, North Carolina, Oklahoma, South Carolina, Tennessee, Texas, Virginia, West Virginia, Washington D.C., and Delaware. The northeastern states included Connecticut, Maine, Massachusetts, New York, New Hampshire, New Jersey, Pennsylvania, Rhode Island, and Vermont.

Before administering the survey, the survey was pretested with a group of 50 homeowners who had purchased lawn fertilizers within the last 12 months. The pretest used the same online software and was used to test the survey instrument and duration before collecting the final sample. The survey lasted $\approx 20 \mathrm{~min}$ and all participants (pretest and study) were compensated for their time via an online points reward system (administered by Qualtrics). 
Given that respondents could indicate that they had purchased fertilizers from several of the fertilizer brand categories, a set of binary logit models and marginal effect estimates were used to better understand the drivers (i.e., important features, retail outlet, and demographics) for each brand category. Binary logit models were used because the dependent variable (brand category) was binary, meaning that if a respondent indicated he or she had purchased the fertilizer brand, one was assigned to that brand category; and zero was assigned if the person did not purchase from that fertilizer brand category. A multinomial logit model would have been an appropriate empirical analysis if the dependent variables were mutually exclusive, meaning the summation of probability was equal to one. However, in this instance, respondents could select multiple fertilizer brands, resulting in a summation greater than onemeaning the binary logit models were more appropriate for the dataset. In total, five binary logit models were estimated, one model per fertilizer brand category. The probabilities associated with the binary logit model were calculated using the following equation:

$$
\operatorname{Prob}(\Upsilon=1 \mid X)=\frac{e^{\beta^{\prime} X}}{1+e^{\beta^{\prime} X}}
$$

where $X$ represents a set of explanatory variables (Greene, 2008). Explanatory variables used in the binary logit models included sociodemographic variables (e.g., age, gender, education, household income, pet ownership, etc.), retail outlet (location of fertilizer purchase), and importance of various fertilizer attributes (e.g., brand, bag size, organic, etc.). The coefficients from the binary logit model represent log-odds with the coefficient sign, indicating an increasing/decreasing odds of purchasing from a specific fertilizer brand category. Next, the marginal effects were estimated and indicate the percent change from the base level for dummy variables and the percent change "given a one-unit increase from the mean" for continuous variables (Campbell et al., 2015). For instance, if the marginal effect was positive and significant, then moving from a value of one (indicating "very unimportant") to a value of two ("somewhat unimportant") would increase the probability of the respondent selecting that brand category by that number of percentage points. This analysis was repeated for each of the five fertilizer brand categories using the corresponding binary logit model, resulting in five sets of marginal effects. In the results section, only the marginal effects are presented and discussed; however, the binary logit model results are available from the corresponding author on request.

\section{Results}

SUMMARY OF DEMOgRAPHIC RESULTS. A total of 1066 homeowners throughout the United States were surveyed using an online survey during Dec. 2013. The sample is not representative of the entire U.S. population because only homeowners with lawns, who fertilize their own lawns, and who had purchased lawn fertilizer within the past 12 months were surveyed. U.S. Census estimates are provided as a guide to illustrate how the sample differs from the overall U.S. population (U.S. Census Bureau, 2018a). With respect to the sociodemographic characteristics of the sample, the sample respondents averaged 49 years of age, with a median age of 51 years (Table 1 ). The median age of the U.S. population is 37.8 years (U.S. Census Bureau, 2018a), which is in-line with the sample's median age when adjusting the U.S. population estimate by removing persons under 18 years of age. The sample respondents' household income averaged between $\$ 60,000$ and $\$ 79,999$, which is slightly higher than the median household income for the United States, which was $\$ 57,652$ in 2017 (U.S. Census Bureau, 2018b). Further, the sample mirrored the overall U.S. population in gender $(51 \% \mathrm{fe}$ male vs. $49 \%$ male), while pet ownership was slightly higher (64\% in the sample vs. $57 \%$ for all U.S. households) (American Veterinary Medical Association, 2012; U.S. Census Bureau, 2018b). Unfortunately, statistical tests cannot be performed to test whether the sample is significantly different from the U.S. population given that standard errors are not reported for continuous demographics (i.e., age) and for other variables [e.g., the census reports age categorically, while survey respondents were asked for continuous responses or vice versa (e.g., household income)].

The most popular brand of fertilizer category was chosen by $69 \%$ of respondents with the primarily turf and other brand categories being chosen by $25 \%$ and $23 \%$ of respondents, respectively (Table 1 ). Only $14 \%$ of respondents chose the sustainable/organic fertilizer brand category, which is like the $7 \%$ of "green buyers" found by Dahlin et al. (2016). Finally, 8\% of respondents could not recall which fertilizer they had purchased.

Sociodemographic characteristics were also estimated for each of the fertilizer brand categories. Pairwise $t$ tests demonstrated statistical differences between the categories' demographics (Table 1). In general, the most popular brand category homeowners were slightly older, with $51 \%$ female. Their education level was lower, while household size and pet ownership was in the middle of the category groups. Income was the second highest among the categories (behind the other brands category). About 17\% were from the western region, 16\% were from the midwestern region, $50 \%$ were from the southern region, and 16\% were from the northeastern region.

The primarily turf fertilizer brands category consisted of younger homeowners, with $49 \%$ female (Table 1). Their education and income levels were in the middle of the other categories. They had the second highest number of adults, children, and pets, behind the sustainable/organic brands category. In terms of residence, 16\% were from the western region of the United States, 10\% were from the midwestern region, $57 \%$ were from the southern region, and $17 \%$ were from the northeastern region.

The sustainable/organic fertilizer brands category was the youngest homeowner group, with the highest percentage of females (Table 1). They were in the middle of the categories in terms of education level but had the highest number of adults, children, and pets within their households. Their income level was second to lowest (behind the "I do not remember the brand" category). About 15\% lived in the western region, $17 \%$ in the 


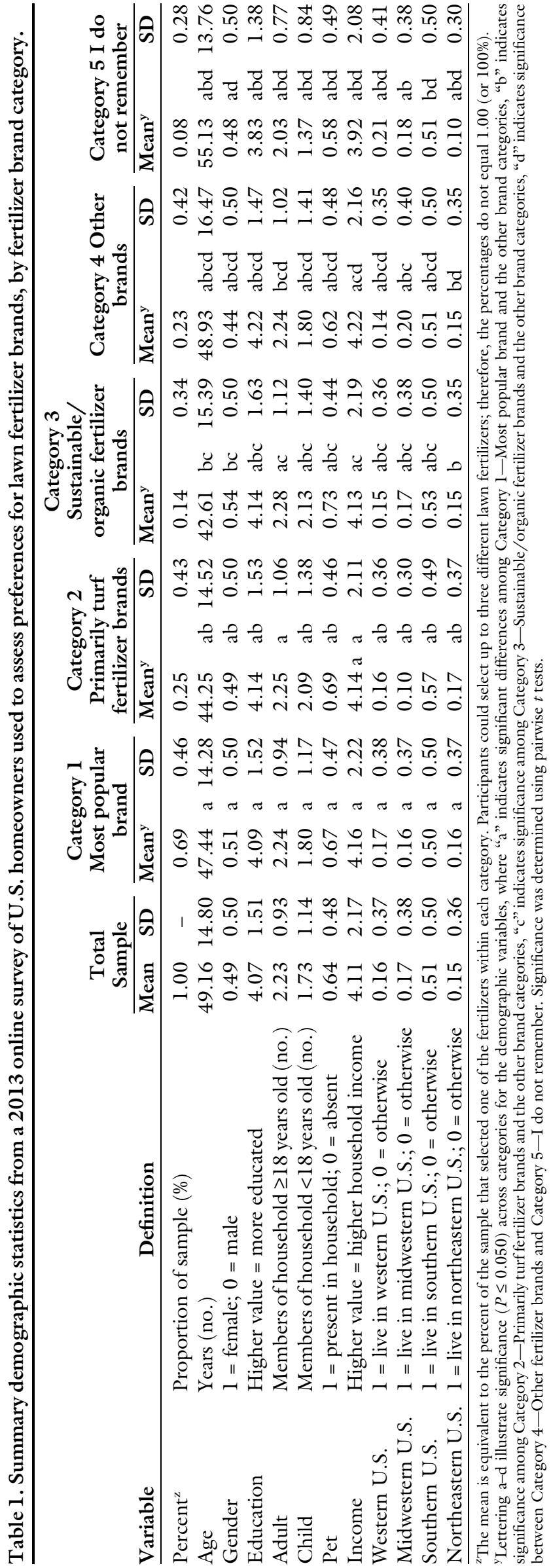

midwestern region, $53 \%$ in the southern region, and $15 \%$ in the northeastern region of the United States.

Homeowners in the other brands category were older and had the highest percentage of males (Table 1). They also had the highest education and income levels. Their household size was comparable to the most popular brand category, and they had lower pet ownership than most of the other categories (except for the "I do not remember the brand" category). In terms of residence, $14 \%$ lived in the western region, $20 \%$ in the midwestern region, $51 \%$ in the southern region, and $15 \%$ in the northeastern region.

The "I do not remember the brand" category consisted of the oldest homeowners, with a high percentage of males (Table 1). They had the lowest education, income, and pet ownership levels. They also had the smallest household sizes (adults and children) relative to the other categories. A larger percentage of respondents lived in the west $(21 \%)$, with $18 \%$ living in the midwest, $51 \%$ in the south, and $10 \%$ in the northeast.

Empirical analysis. Next, the relationships between important fertilizer attributes, demographics, and fertilizer brand category selection will be shown, using binary logit models and marginal effects. For the most popular brand category, for each unit increase in the importance of brand, the respondent was $6.9 \%$ points more likely to choose the most popular brand (Table 2). Each unit increase in fertilizer attributes (such as the importance of having an insecticide included, correct bag size, or being pet- and kid-friendly) increased selection likelihood (by 3.7\%, 3.3\%, and $2.6 \%$ points, respectively). Increased importance of organic and quick acting attributes also improved selection likelihood. On the other hand, each unit increase in the importance of price decreased the probability of selection of the most popular brand by $4.7 \%$ points; while each unit increase in the importance of the $\mathrm{N}-\mathrm{P}-\mathrm{K}$ ratio or fertilizer effect longevity decreased the probability of selection by $2.7 \%$ points. Other attributes that decreased probability of selection 
Table 2. Marginal effect estimates from five binary logit models investigating if important fertilizer attributes, frequented retail outlets, and demographic variables impact U.S. homeowners' lawn fertilizer brand category selection $(\mathbf{n}=1066)$.

\begin{tabular}{|c|c|c|c|c|c|c|c|c|c|c|}
\hline \multirow[b]{2}{*}{ Variables $^{\mathrm{zy}}$} & \multicolumn{2}{|c|}{$\begin{array}{l}\text { Category } 1 \\
\text { Most popular } \\
\text { brand }\end{array}$} & \multicolumn{2}{|c|}{$\begin{array}{c}\text { Category } 2 \\
\text { Primarily turf } \\
\text { fertilizer } \\
\text { brands }\end{array}$} & \multicolumn{2}{|c|}{$\begin{array}{c}\text { Category } 3 \\
\text { Sustainable/ } \\
\text { organic } \\
\text { fertilizer } \\
\text { brands }\end{array}$} & \multicolumn{2}{|c|}{$\begin{array}{c}\text { Category } 4 \\
\text { Other fertilizer } \\
\text { brands }\end{array}$} & \multicolumn{2}{|c|}{$\begin{array}{l}\text { Category } 5 \text { I } \\
\text { don't } \\
\text { remember the } \\
\text { brand }\end{array}$} \\
\hline & $\mathrm{dy} / \mathrm{dx}^{\mathrm{x}}$ & SE & $\mathrm{dy} / \mathrm{dx}$ & SE & $\mathrm{dy} / \mathrm{dx}$ & SE & $\mathrm{dy} / \mathrm{dx}$ & SE & $\mathrm{dy} / \mathrm{dx}$ & SE \\
\hline Nitrogen-phosphorus-potassium ratio & -0.027 & 0.002 & -0.009 & 0.002 & 0.010 & 0.001 & 0.033 & 0.002 & 0.004 & 0.001 \\
\hline Brand & 0.069 & 0.002 & 0.013 & 0.002 & -0.022 & 0.001 & -0.024 & 0.002 & -0.029 & 0.001 \\
\hline Bag size & 0.033 & 0.002 & -0.042 & 0.002 & 0.007 & 0.001 & 0.004 & 0.002 & 0.000 & 0.001 \\
\hline Price & -0.047 & 0.002 & 0.004 & 0.002 & -0.004 & 0.001 & -0.007 & 0.002 & 0.025 & 0.001 \\
\hline Organic & 0.016 & 0.002 & 0.020 & 0.001 & 0.046 & 0.001 & 0.004 & 0.001 & -0.012 & 0.000 \\
\hline Controlled-release nitrogen & -0.007 & 0.002 & 0.051 & 0.002 & 0.019 & 0.001 & 0.007 & 0.002 & -0.022 & 0.001 \\
\hline Insecticide included & 0.037 & 0.002 & 0.037 & 0.002 & 0.003 & 0.001 & -0.017 & 0.002 & 0.000 & 0.001 \\
\hline Herbicide included & -0.013 & 0.002 & 0.005 & 0.002 & 0.001 & 0.001 & 0.017 & 0.002 & -0.003 & 0.000 \\
\hline Pet- and kid-friendly & 0.026 & 0.002 & -0.042 & 0.001 & -0.012 & 0.001 & -0.021 & 0.001 & 0.008 & 0.000 \\
\hline Fertilizer effect longevity & -0.027 & 0.003 & 0.007 & 0.003 & -0.003 & 0.002 & 0.000 & 0.003 & -0.006 & 0.001 \\
\hline Quick acting & 0.014 & 0.002 & -0.031 & 0.002 & -0.023 & 0.001 & -0.009 & 0.002 & 0.005 & 0.001 \\
\hline Water smart & -0.007 & 0.002 & -0.002 & 0.002 & 0.006 & 0.002 & 0.009 & 0.002 & 0.004 & 0.001 \\
\hline \multicolumn{11}{|l|}{ Retail outlet most frequented } \\
\hline Independent garden center & -0.017 & 0.004 & 0.129 & 0.004 & 0.072 & 0.002 & 0.099 & 0.003 & 0.010 & 0.001 \\
\hline Supermarket/grocery store & 0.031 & 0.006 & 0.160 & 0.004 & 0.053 & 0.003 & 0.220 & 0.004 & -0.007 & 0.002 \\
\hline Home improvement/hardware store & 0.191 & 0.005 & 0.213 & 0.005 & 0.131 & 0.003 & 0.054 & 0.004 & -0.031 & 0.001 \\
\hline Mass merchandiser/wholesale club & 0.205 & 0.005 & 0.077 & 0.004 & 0.046 & 0.002 & 0.062 & 0.003 & -0.026 & 0.002 \\
\hline Internet & 0.012 & 0.016 & -0.035 & 0.011 & -0.053 & 0.006 & 0.170 & 0.010 & 0.024 & 0.004 \\
\hline Other & -0.192 & 0.011 & 0.055 & 0.011 & 0.027 & 0.008 & 0.291 & 0.008 & -0.038 & 0.003 \\
\hline \multicolumn{11}{|l|}{ U.S. region } \\
\hline West & 0.046 & 0.006 & -0.042 & 0.005 & -0.003 & 0.003 & -0.033 & 0.005 & 0.036 & 0.002 \\
\hline Midwest & -0.032 & 0.005 & -0.136 & 0.005 & 0.022 & 0.003 & 0.042 & 0.005 & 0.020 & 0.002 \\
\hline South & -0.011 & 0.005 & 0.006 & 0.004 & 0.011 & 0.003 & 0.012 & 0.004 & 0.026 & 0.002 \\
\hline Northeast & Base & & Base & & Base & & & & Base & \\
\hline \multicolumn{11}{|l|}{ Demographics } \\
\hline Age & -0.003 & 0.000 & -0.003 & 0.000 & -0.002 & 0.000 & 0.001 & 0.000 & 0.001 & 0.000 \\
\hline Gender & 0.020 & 0.003 & -0.029 & 0.003 & 0.001 & 0.002 & -0.041 & 0.003 & 0.003 & 0.001 \\
\hline Education & 0.012 & 0.001 & 0.003 & 0.001 & 0.000 & 0.001 & 0.006 & 0.001 & -0.008 & 0.000 \\
\hline Adult & -0.008 & 0.002 & -0.003 & 0.001 & 0.005 & 0.001 & 0.006 & 0.001 & -0.010 & 0.001 \\
\hline Child & -0.010 & 0.002 & 0.046 & 0.001 & 0.019 & 0.001 & 0.011 & 0.001 & -0.006 & 0.001 \\
\hline Pet & 0.064 & 0.003 & 0.047 & 0.003 & 0.019 & 0.002 & -0.006 & 0.003 & -0.006 & 0.001 \\
\hline Income & -0.001 & 0.001 & -0.010 & 0.001 & -0.006 & 0.000 & -0.001 & 0.001 & 0.005 & 0.000 \\
\hline
\end{tabular}

included herbicide included, controlled-release $\mathrm{N}$, and water smart technology. Regarding how the retail outlet impacts brand selection, respondents who usually purchase lawn fertilizers from mass merchandiser/ wholesale clubs, home improvement/hardware stores, or supermarket/grocery stores were $20.5 \%$, $19.1 \%$, and $3.1 \%$ points more likely to select the most popular brand, compared with those respondents who do not purchase from those outlets. Respondents who usually purchase lawn fertilizers from other retail outlets or independent garden centers were $19.2 \%$ and $1.7 \%$ points less likely to select the most popular brand. There could be several reasons for this finding. For instance, independent garden centers may push higher-margin fertilizer brands, while more mainstream outlets may focus on selling a larger quantity of fertilizers. A second potential explanation is that the most popular brand is readily available at mainstream outlets, while specialty stores (such as independent garden centers) offer a variety of specialized fertilizers resulting in more diversity in options and selection.

With respect to sociodemographics, respondents living in the western states region were $4.6 \%$ points more likely to select the most popular brand, compared with those living in northeastern states (Table 2). Conversely, respondents living in midwestern or southern states were $3.2 \%$ and $1.1 \%$ points less likely to select the most popular brand, compared with individuals in the northeastern states. Likely this reflects regional differences in terms of local fertilizer ordinances, community standards (i.e., lawn and landscape appearances), and soil/environmental conditions (Khachatryan et al., 2016; Martini et al., 2015; Suh et al., 2016). Females were 2.0\% points more likely to select the most popular brand compared with males (Table 2 ). For each category increase 
in education level, the respondent was $1.2 \%$ points more likely to select the most popular brand. Additionally, pet owners were $6.4 \%$ points more likely to select the most popular brand compared with non-owners. Conversely, each additional child or adult in the household decreased probability of selection by $1.0 \%$ and $0.8 \%$ points. Additionally, older respondents were less likely to select the most popular brand than younger consumers. This finding is interesting given older consumers are the primary homeowners in the United States as well as the primary plant purchasers (Baldwin, 2015; Butterfield, 2004; Dennis and Behe, 2007; U.S. Census Bureau, 2019b). It is possible older consumers are more familiar with fertilizer choices and are tailoring their selections to their specific needs by purchasing products other than the popular brand. From a marketing context there are two potential implications. The most popular brand could increase efforts to maintain younger consumers, who are a growing force in the marketplace. Or the popular brand could make efforts to attract older consumers, who most likely have more spending power. This is interesting because, on the one hand, younger consumers are beginning to make up a larger percent of the marketplace and are an underserved customer group (Butterfield, 2004). However, older consumers generally have more discretionary income to spend on fertilizers and are (traditionally) the core consumers of gardening-related goods (Baldwin, 2015; Butterfield, 2004; Dennis and Behe, 2007). This point is especially important given that young consumers are becoming first-time homeowners, meaning they have lawns that need to be maintained.

Several fertilizer attributes increased selection likelihood for the primarily turf fertilizer brand category. For each unit increase in the importance of the controlled-release $\mathrm{N}$ attribute, respondents were $5.1 \%$ points more likely to choose the primarily turf fertilizer brands (Table 2 ). Respondents were also more likely to select the primarily turf fertilizer brands if they perceived insecticide included, organic, brand, effect longevity, herbicide included, and price as important. As bag size or the pet- and kid-friendly attributes increased in importance, respondents were $4.2 \%$ points less likely to select the primarily turf brands. Additionally, as quick acting and $\mathrm{N}-\mathrm{P}-\mathrm{K}$ ratio became more important, likelihood of selecting the primarily turf fertilizer brands decreased. Respondents who purchased lawn fertilizers from brickand-mortar stores were more likely to select primarily turf fertilizer, with the home improvement or hardware stores increasing selection likelihood by $21.3 \%$ points. Respondents who purchase from Internet sources were $3.5 \%$ points less likely to select these fertilizers. Respondents living in the western or midwestern regions were less likely to select these brands, while southern and northeastern region respondents showed a similar probability of selection. Individuals with pets, children, and higher educations were more likely to select brands within this category. Conversely, females, older respondents, additional adults within the household, and those with higher incomes decreased probability of selection.

Not surprisingly, as the importance of the organic attribute increased, respondents' selection likelihood for the sustainable/organic fertilizer brands category increased by $4.6 \%$ points (Table 2 ). Additionally, for each unit increase in the level of importance to respondents for the five attributes of controlled-release $\mathrm{N}, \mathrm{N}-\mathrm{P}-\mathrm{K}$ ratio, bag size, water smart technology, and insecticide included, there was improved selection likelihood for a brand within the category of sustainable/organic fertilizer brands. Attributes that decreased likelihood of selection for the sustainable/organic fertilizer brands included quick acting, brand, pet- and kid-friendly, and price. Respondents who purchased fertilizers from brick-and-mortar retail outlets were more likely to select these brands, while the use of Internet sources decreased selection likelihood. Individuals from the midwestern or southern regions were more likely to select these brands than those respondents from the northeastern region. There were no significant differences between the western and northeastern regions. As household size (i.e., number of adults and children) increased, so did selection likelihood. Pets also increased selection likelihood. However, older respondents and those with higher household incomes were less likely to select brands within this category.

The most important fertilizer attribute for the other fertilizer brands category was the $\mathrm{N}-\mathrm{P}-\mathrm{K}$ ratio, which increased probability of selection by $3.3 \%$ points for each unit of increase (Table 2). Other attributes that increased probability of selection included herbicide included, water smart technology, controlled-release $\mathrm{N}$, brand, and organic. Attributes that decreased selection likelihood included brand, pet- and kid-friendly, insecticide included, and price. The influence of retail outlets frequented for fertilizer purchases was consistent and positive across the different outlet types, with other outlets, supermarket/grocery stores, and Internet sources increasing likelihood of selection by $29.1 \%, 22.0 \%$, and $17.0 \%$ points, respectively. Individuals living in midwestern or southern states were more likely to select brands within this category than those respondents in northeastern states. However, respondents in western states were less likely to select these brands than northeastern respondents. Sociodemographic attributes that increased probability of selection included being older, a higher education level, and a larger household size (i.e., number of adults and children). Females and individuals with pets were less likely to select these brands.

Respondents who did not remember the brand of fertilizer they purchased tended to perceive price, pet- and kid-friendly, quick acting, water smart, and $\mathrm{N}-\mathrm{P}-\mathrm{K}$ ratio as important (Table 2). Fertilizer attributes that decreased probability of selecting the "I do not remember the brand" category included brand, controlled-release $\mathrm{N}$, organic, effect longevity, and herbicide included. Respondents who frequently purchased from Internet sources or independent garden centers were $2.4 \%$ and $1.0 \%$ points more likely to select "I do not remember the brand" category. Conversely, frequently purchasing from other outlets, mass merchandiser/wholesale clubs, home improvement/hardware stores, and supermarket/grocery stores decreased likelihood of selection. These results may be related to product offerings available at the particular 
retail outlets. For instance, consumers at independent garden centers may purchase lesser known, boutique, or store brand fertilizers - cases in which the brand name is not necessarily remembered, but the consumer knows where to shop to obtain the desired fertilizer. Alternatively, consumers of independent garden centers may rely upon staff assistance or recommendations rather than brand recognition when selecting products. For instance, Campbell and Campbell (2019) found that independent garden centers are perceived to have more knowledgeable staff and better customer service than home improvement centers and mass merchandisers. Respondents living in the western, midwestern, and southern regions were more likely to select this category than those in the northeastern region. Younger consumers, females, and individuals with higher incomes were more likely to select this category; while factors of higher education, larger households (adults and children), and pet ownership decrease selection likelihood.

\section{Discussion and conclusion}

An increased understanding of how consumer perceptions and sociodemographics impact choice of lawn fertilizer brands can aid in positioning products and brands to attract consumers. This research evaluates how respondents from a nationwide survey choose lawn fertilizer brand categories and how different factors impact those choices. The results showed that lawn fertilizer attributes strongly influence respondents' likelihood of selecting the different brand options, which provides industry stakeholders with insights into what attributes consumers value and focus on when considering different choices. This information can be used in marketing efforts and product development programs. For instance, for the most popular brand category, the brand name, insect control, and bag size positively impacted selection likelihood. Conversely, price, $\mathrm{N}-\mathrm{P}-\mathrm{K}$ ratio, and effectiveness longevity negatively impacted selection. This may imply that this brand category is selected when an issue arises that requires immediate action but not necessarily long-term action. As such, this brand may be a "go to" brand for relatively quick results. This implies there is potential for popular brands to use marketing efforts to leverage the perception of gaining results quickly and effectively.

If turf fertilizer brands category is of interest, there is opportunity to include and promote attributes that control pests (insecticides, herbicides), while having nutrient longevity (controlled-release N). Both of these factors improve ease of use. This may be of particular interest when maintaining a homogenous turfgrass lawn. Organic was also viewed positively and may relate back to stronger regulations and standards, or perceptions of improving the soil's organic content, which would improve plant/ turf health.

Interestingly, the study finds that price and brand importance play pivotal roles in the selection of a fertilizer. Notably, as brand importance decreases, respondents were more apt to choose fertilizer brands that are more specialized, including sustainable/organic fertilizer brands. As noted by Dahlin et al. (2016) and Suh et al. (2016), consumer segments exist that value ecofriendly or green fertilizers. For the sustainable/organic brands category, practical information was important $(\mathrm{N}-\mathrm{P}-\mathrm{K}$ ratio, bag size), which may be related to fertilizers that are marketed as sustainable, natural, or organic, offering a variety of nutrient ratios and coming in a variety of different sizes. Marketing efforts that emphasize the $\mathrm{N}-\mathrm{P}-\mathrm{K}$ ratio may aid in attracting consumers to the sustainable/organic fertilizer brands category.

The other brand and the "I don't remember" categories were also influenced by the attributes. The other brand was primarily impacted by the $\mathrm{N}-\mathrm{P}-\mathrm{K}$ ratio. This may indicate it is viewed as utilitarian or for general maintenance. The "I don't remember the brand" category was primarily selected based on the price, $\mathrm{N}-\mathrm{P}-\mathrm{K}$ ratio, pet- and kid-friendly, quick acting, and water smart. This may imply that people who purchase these items were more driven by attributes than by specific brands when selecting their products. If a fertilizer company was interested in attracting these individuals, price-based promotions would likely be the primary focal point in marketing efforts, followed by effectiveness and safety. This is supported by Dahlin et al. (2016), who found two price-sensitive buyer segments in the fertilizer industry.

With respect to sociodemographic factors, older respondents were less likely to select brands from the popular, primarily turf, and sustainable/organic brand categories, compared with younger respondents. Given that older consumers are the core consumer of gardening-related products, this finding may reflect that they have greater familiarity with or potential preferences for alternative fertilizer options not included in this study (e.g., other brands, homemade options, etc.). This explanation is supported by this study's results indicating that older consumers are more likely to select other fertilizer brand and the "I don't remember the brand" category. The presence of children or pets increased the probability of selecting primarily turf or sustainable/organic fertilizer brand categories. Respondents shopping online were more likely to select "other" fertilizer brands or "I do not remember," while being less likely to purchase a primarily turf brand or a sustainable/organic brand. Shopping at a most other retail outlets had a positive impact on selection likelihood, except for the most popular brand category at independent garden centers or other retailers. These results may reflect availability or consumers' assumptions of availability. Firms can use this information to align their product positioning with consumer expectations.

In conclusion, fertilizer producers and retailers can use these results to aid in tailoring their marketing strategies to increase consumer awareness and sales. Notably, the most popular brand category could potentially work to capture an older clientele by stressing the importance of the brand, bag size availability, and the pet- and kid-friendly nature of their product. Other brands and primarily turf brands could benefit from emphasizing attributes that consumers value, such as $\mathrm{N}-\mathrm{P}-\mathrm{K}$ ratio and controlled-release N. Sustainable/organic brands could emphasize organic production and highlight other value-added attributes, including controlled-release N. Enacting strategies associated with these findings 
should garner increased awareness as well as increased sales.

As with most studies, there are limits to the current work. First, an online survey was used to collect data, which is subject to the same issues as other online surveys (Cobanoglu et al., 2001). Specifically, hypothetical bias could potentially be an issue because real economic consequences were not used in the methodology. Additionally, online surveys foster the potential inclusion of professional survey takers and possible sampling bias because not all homeowners were surveyed (e.g., lack of Internet access, etc.). However, the benefits of an online data collection method (i.e., quick/accurate responses, reduced human error, wide geographic area coverage, inexpensive to conduct, etc.) outweigh potential drawbacks of the methodology. Furthermore, online surveys have been used successfully in many other studies addressing consumer behavior (Campbell and Campbell, 2019; Campbell et al., 2016; Dahlin et al., 2016; Khachatryan et al., 2016; Suh et al., 2016). The researchers also incorporated screening and validation questions to minimize the number of professional survey takers. A second limitation is that the lawn fertilizer brand data were based on respondent recall rather than actual sales data. The inclusion of real sales data would be an interesting follow-up study to test the robustness of the results. Finally, a caveat to this article is that the data are several years old (2013). Again, there is an opportunity to conduct additional studies and incorporate new value-added attributes (e.g., biodegradable plastic, carbon neutral, etc.) to identify how consumer behavior might change based on those factors. Despite these limitations, the survey results provide a better understanding of the fertilizer market and can aid industry stakeholders as they determine branding and marketing strategies to attract homeowners.

\section{Literature cited}

American Veterinary Medical Association. 2012. Pet ownership and demographics sourcebook. 21 Aug. 2018. <https://www. avma.org/KB/Resources/Statistics/Pages/ Market-research-statistics-US-pet-ownership. aspx>.
Baldwin, I. 2015. National gardening survey highlights need for change in retail industry. 10 Jan. 2019. <http://ianbaldwin. com/wordpress/wp-content/uploads/ 2012/06/NGS_2014NeedForChangein RetailIndustry.pdf $>$.

Bandaranayake, W., Y.L. Qian, W.J. Parton, D.S. Ojima, and R.F. Follett. 2003. Estimation of soil organic carbon changes in turfgrass systems using the CENTURY model. Agron. J. 95:558-563.

Beard, J.B. 1999. Turfgrass benefits and the golf environment, p. 36-44. In: J.M. Clark and M.P. Kenna (eds.). Fate and management of turfgrass chemicals. Oxford Univ. Press, Oxford, UK.

Beard, J.B. and R.L. Green. 1994. The role of turfgrasses in environmental protection and their benefits to humans. J. Environ. Qual. 23(3):452-460.

Berndt, W.L., P.E. Rieke, and J.M. Vargas, Jr. 1990. Kentucky bluegrass thatch characteristics following application of bio-organic materials. HortScience 25:412-414.

Beverly, R.B., W. Florkowski, and J.M. Ruter. 1997. Fertilizer management by landscape maintenance and lawn care firms in Atlanta. HortTechnology 7:442445.

Bruneau, A.H., F. Yelverton, L.T. Lucas, and R.L. Brandenburg. 2008. Organic lawn care: A guide to lawn maintenance and pest management for North Carolina. North Carolina Coop. Ext. Serv., College Agr. Life Sci., North Carolina State Univ., Raleigh.

Butterfield, B.W. 2004. National Gardening Association survey 2003. Natl. Gardening Assn., Burlington, VT.

Campbell, B.L., H. Khachatryan, C. Hall, B.K. Behe, and J. Dennis. 2016. Crunch the can or throw the bottle? Effect of "bottle deposit laws" and municipal recycling programs. Resour. Conserv. Recycling 106:98-109.

Campbell, B., H. Khachatryan, B.K. Behe, J.H. Dennis, and C.R. Hall. 2015. Consumer perceptions of eco-friendly and sustainable terms. Agr. Resour. Econ. Rev. 44(1):21-34.

Campbell, J. and B. Campbell. 2019. Consumer perceptions of green industry retailers. HortTechnology 29:213-222.

Carey, R.O., G.J. Hochmuth, C.J. Martinez, T.H. Boyer, V.D. Nair, M.D. Dukes, G.S. Toor, A.L. Shober, J.L. Cisar, L.E. Trenholm, and J.B. Sartain. 2012. A review of turfgrass fertilizer management practices: Implications for urban water quality. HortTechnology 22:280-291.
Carrico, A.R., J. Fraser, and J.T. Bazuin. 2013. Green with envy: Psychological and social predictors of lawn fertilizer application. Environ. Behav. 45(4):427-454.

Cheng, Z., P.S. Grewal, B.R. Stinner, K.A. Hurto, and H.B. Hamza. 2008. Effects of long-term turfgrass management practices on soil nematode community and nutrient pools. Appl. Soil Ecol. 38(2):174-184.

Cobanoglu, C., B. Warde, and P.J. Moreo. 2001. A comparison of mail, fax and web-survey methods. Intl. J. Mktg. Res. 43(4):441-452.

Cook, E.M., S.J. Hall, and K.L. Larson. 2012. Residential landscapes as socialecological systems: A synthesis of multiscalar interactions between people and their home environment. Urban Ecosyst. 15(1):19-52.

Dahlin, J., V. Halbherr, P. Kurz, M. Nelles, and C. Herbes. 2016. Marketing green fertilizers: Insights into consumer preferences. Sustainability 8(11):1169.

Dennis, J.H. and B.K. Behe. 2007. Evaluating the role of ethnicity on gardening purchases and satisfaction. HortScience 42:262-266.

Dillman, D., J. Smyth, and L. Christian. 2009. Internet, mail, and mixed-mode surveys: The tailored design method. Wiley, Hoboken, NJ.

Duble, R.L. 1996. Turfgrasses: Their management and use in the southern zone. 2nd ed. Texas A\&M Univ. Press, College Station, TX.

Easton, Z.M. and A.M. Petrovic. 2004. Fertilizer source effect on ground and surface water quality in drainage from turfgrass. J. Environ. Qual. 33(2):645655 .

Groffman, P.M., J.M. Grove, C. Polsky, N.D. Bettez, J.L. Morse, J. CavenderBares, S.J. Hall, J.B. Heffernan, S.E. Hobbie, K.L. Larson, C. Neill, K. Nelson, L. Ogden, J. O'Neil-Dunne, D. Pataki, R. Roy Chowdhury, and D.H. Locke. 2016. Satisfaction, water and fertilizer use in the American residential macrosystem. Environ. Res. Lett. 11:034004.

Greene, W. 2008. Econometric analysis. 6th ed. Prentice Hall, Englewood Cliffs, NJ.

Hochmuth, G., T. Nell, J.B. Unruh, L. Trenholm, and J. Sartain. 2012. Potential unintended consequences associated with urban fertilizer bans in Florida-A scientific review. HortTechnology 22:600616.

Khachatryan, H., D.H. Suh, G. Zhou, and M. Dukes. 2016. Sustainable urban landscaping: Consumer preferences and 
willingness to pay for turfgrass fertilizers. Can. J. Agr. Econ. 65(3):385-407.

King, K.W., J.C. Balogh, K.L. Hughes, and R.D. Harmel. 2007. Nutrient load generated by storm event runoff from a golf course watershed. J. Environ. Qual. 36(4):1021-1030.

Kjelgren, R., L. Rupp, and D. Kilgren. 2000. Water conservation in urban landscapes. HortScience 35:1037-1043.

Lal, R. 2004. Soil carbon sequestration impacts on global climate change and food security. Science 304(5677):16231627.

Larson, K.L., K.C. Nelson, S.R. Samples, S.J. Hall, N. Bettez, J. Cavender-Bares, P.M. Groffman, M. Grove, J.B. Heffernan, S.E. Hobbie, J. Learned, J.L. Morse, C. Neill, L.A. Ogden, J. O’Neil-Dunne, D.E. Pataki, C. Polsky, R. Roy Chowdhury, M. Steele, and T.L.E. Trammell. 2016. Ecosystem services in managing residential landscapes: Priorities, value dimensions, and cross-regional patterns. Urban Ecosyst. 19(1):95-113.

Liu, L.X., T. Hsiang, K. Carey, and J.L. Eggens. 1995. Microbial populations and suppression of dollar spot disease in creeping bentgrass with inorganic and organic amendments. Plant Dis. 79(2): 144-147.

Martini, N.F., K.C. Nelson, S.E. Hobbie, and L.A. Baker. 2015. Why "feed the lawn"? Exploring the influences on residential turf grass fertilization in the Minneapolis-Saint Paul metropolitan area. Environ. Behav. 47(2):158-183.

McCoy, E.L. 1998. Sand and organic amendment influences on soil physical properties related to turf establishment. Agron. J. 90(3):411-419.

McCullough, D. 1998. Web-based market research: The dawning of a new age. Direct Mktg. 61(8):36-38

Milesi, C., S.W. Running, C.D. Elvidge, J.B. Dietz, B.T. Tuttle, and R.R. Nemani. 2005. Mapping and modeling the biogeochemical cycling of turf grasses in the United States. Environ. Manage. 36(3):426-438.
Miller, K.L. 2012. State law banning phosphorus fertilizer use. OLR Res. Rep. 2022-R-0076. 10 Jan. 2019. <http:// www.cga.ct.gov $/ 2012 / \mathrm{rpt} / 2012-\mathrm{R}$ 0076.htm>

Morris, J. and J. Bagby. 2008. Measuring environmental value for natural lawn and garden care practices. Intl. J. Life Cycle Assess. 13(3):226-234.

Polsky, C., J.M. Grove, C. Knudson, P.M. Groffman, N. Bettez, J. Cavender-Bares, S.J. Hall, J.B. Heffernan, S.E. Hobbie, K.L. Larson, J.L. Morse, C. Neill, K.C. Nelson, L.A. Ogden, J. O’Neil-Dunne, D.E. Pataki, R. Roy Chowdhury, and M.K. Steele. 2014. Assessing the homogenization of urban land management with an application to US residential lawn care. Proc. Natl. Acad. Sci. USA 111 (12): $4432-4437$

Priest, M.W., D.J. Williams, and H.A. Bridgman. 2000. Emissions from in-use lawn-mowers in Australia. Atmos. Environ. 34(4):657-664.

Qian, Y. and R.F. Follett. 2002. Assessing soil carbon sequestration in turfgrass systems using long-term soil testing data. Agron. J. 94(4):930-935.

Reid, S.B., E.K. Pollard, D.C. Sullivan, and S.L. Shaw. 2010. Improvements to lawn and garden equipment emissions estimates for Baltimore, Maryland. J. Air Waste Mgt. Assoc. 60(12):1452-1462.

Robbins, P. and T. Birkenholtz. 2003. Turfgrass revolution: Measuring the expansion of the American lawn. Land Use Policy 20(2):181-194.

Robbins, P. and J.T. Sharp. 2003. Producing and consuming chemicals: The moral economy of the American lawn. Econ. Geogr. 79(4):425-451.

Suh, D.H., H. Khachatryan, and Z. Guan. 2016. Why do we adopt environmentally friendly lawn care? Evidence from do-ityourself consumers. Appl. Econ. 48(27): 2550-2561.
U.S. Census Bureau. 2018a. Annual estimates of the resident population by sex, age, race, and Hispanic origin for the United States and states: 1 Apr. 2010 to 1 July 2017. 12 Dec. 2018. <https:// factfinder.census.gov/faces/nav/jsf/ pages/index.xhtml>

U.S. Census Bureau. 2018b. Quickfacts: United States. 11 Jan. 2019. <https:// www.census.gov/quickfacts/fact/table/ US/SEX255217>.

U.S. Census Bureau. 2019a. Census regions and divisions of the U.S. 11 Jan. 2019. <https://www2.census.gov/geo/ pdfs/maps-data/maps/reference/us regdiv.pdf $>$.

U.S. Census Bureau. 2019b. Quarterly residential vacancies and homeownership, second quarter 2019. 15 Aug. 2019. <https://www.census.gov/housing/ hvs/files/currenthvspress.pdf>.

Wallace, V., C. Bartholomew, and J.H. Campbell. 2016. Turf manager response to changing pesticide regulations. HortScience 51:394-397.

Wheeler, M.M., C. Neill, P.M. Groffman, M. Avolio, N. Bettez, J. Cavender-Bares, R.R. Chowdhury, L. Darling, J.M. Grove, S.J. Hall, J.B. Heffernan, S.E. Hobbie, K.L. Larson, J.L. Morse, K.C. Nelson, L.A. Ogden, J. O'Neil-Dunne, D.E. Pataki, C. Polsky, M. Steele, and T.L.E. Trammell. 2017. Continental-scale homogenization of residential lawn plant communities. Landsc. Urban Plan. 165: 54-63.

World Health Organization. 2016. Urban green spaces and health: A review of evidence. 3 Jan. 2019. <http://www. euro.who.int/_data/assets/pdf_file/ 0005/321971/Urban-greenspaces-andhealth-review-evidence.pdf?ua $=1>$. 